\title{
In silico Identification and Functional Characterization of Conserved miRNAs in Fibre Biogenesis Crop Corchorus capsularis
}

\author{
Mahmudul Hasan ${ }^{1,2^{*}}$, Milad Ahmed ${ }^{1,3}$, Foeaz Ahmed ${ }^{1,4}$, Jamil Ahmed ${ }^{1,5}$, Mst Rubaiat Nazneen
} Akhand $^{1,5}$, Kazi Faizul Azim ${ }^{1,6}$, Md. Abdus Shukur Imran ${ }^{1,2}$, Syeda Farjana Hoque ${ }^{1,2}$

${ }^{1}$ Faculty of Biotechnology and Genetic Engineering, Sylhet Agricultural University, Sylhet-3100, Bangladesh;

${ }^{2}$ Department of Pharmaceuticals and Industrial Biotechnology, Sylhet Agricultural University, Sylhet-3100, Bangladesh;

${ }^{3}$ Department of Animal and Fish Biotechnology, Sylhet Agricultural University, Sylhet3100, Bangladesh;

${ }^{4}$ Department of Molecular Biology and Genetic Engineering, Sylhet Agricultural University, Sylhet-3100, Bangladesh;

${ }^{5}$ Department of Biochemistry and Chemistry, Sylhet Agricultural University, Sylhet-3100, Bangladesh;

${ }^{6}$ Department of Microbial Biotechnology, Sylhet Agricultural University, Sylhet-3100, Bangladesh;

\section{*Corresponding author:}

\author{
Mahmudul Hasan \\ Assistant Professor \\ Department of Pharmaceuticals and Industrial Biotechnology \\ Faculty of Biotechnology and Genetic Engineering \\ Sylhet Agricultural University, Sylhet-3100. \\ E-mail: mhasan.pib@sau.ac.bd \\ ORCID ID: https://orcid.org/0000-0003-4761-2111
}




\title{
In silico Identification and Functional Characterization of Conserved miRNAs in Fibre Biogenesis Crop Corchorus capsularis
}

\begin{abstract}
:
Corchorus capsularis, commonly known as jute occupies the leading position in the production of natural fibre and fibre based products alongside lower environmental threat. Nowadays, the study of lignin biosynthesis pathways with other molecular basis of fibres formation are being more focused for its economic perspective. Small noncoding 21 to 24 nt nucleotides long microRNAs play significant roles in regulating the gene expression as well as different functions in cellular growth and development. Here, the study adopted a comprehensive in silico approach to identify and characterize the conserved miRNAs in the genome of C. capsularis including specific gene targets involved in the crucial cellular process. Expressed Sequence Tags (ESTs) based homology search of 3350 known miRNAs of dicotyledons were allowed against 763 nonredundant ESTs of jute genome resulted in the prediction of 5 potential miRNA candidates belonging five different miRNA families (miR1536, miR9567-3p, miR4391, miR11300, and miR8689). The putative miRNAs were 18 nucleotide length, within a range of -0.49 to -1.56 MFEI values and $55 \%$ to $61 \%$ of $(\mathrm{A}+\mathrm{U})$ content of their correspondence pre-miRNAs. A total of 1052 gene targets of putative miRNAs were identified and their functions were extensively analyzed. Most of the gene targets were involved in plant growth, cell cycle regulation, organelle synthesis, developmental process and environmental responses. The five gene targets, namely, NAC Domain Containing Protein, WRKY DNA binding protein, 3-dehydroquinate synthase, Sadenosyl-L-Met-dependent methyl transferase and Vascular-related NAC-Domain were found to be involved in the lignin biosynthesis, phenylpropanoid pathways and secondary wall formation which could play significant roles in the overall fibre biogenesis. The characterization of conserved miRNAs and their functional annotation of specific gene targets might enhance the more miRNA discovery, strengthening the complete understanding of miRNAs association in the cellular basis of lignin biosynthesis towards the production of high standard jute products.
\end{abstract}

Keywords: Corchorus capsularis; Jute; MicroRNA; ESTs, Natural Fibre; Lignin. 


\section{Introduction}

Jute, natural fibre is the blessing of future economy on account of raising awareness with environmental and SDG (Sustainable Development Goal) issues around all over the world $[1,2,3]$.

It is now placed in the second and only after cotton in case of economic importance among the natural fibers and over $95 \%$ of the global jute production is served by India, Bangladesh, China, Nepal and Thailand [4]. Jute products are more environmentally sound and their disposal stage is also less harmful to environment than its competing synthetic materials [5]. Moreover, the natural fibre products are likely to be the favorable for combating against global worming rather [6]. Moreover, on an average farm value of $\sim$ US $\$ 2.3$ billion is being generated by the jute products annually [7]. Now-a-days, scientists are more likely to be interested in developing environment-friendly and cost-effective polymer matrix composites from natural resources as implementation of new laws and raising pressure from environmental activists [8,9,10,11]. Recently, genome sequencing of different bast (phloem) fibres plants such as Jute (Corchorus sp.) and kenaf (Hibiscus cannabinus L.) has been completed focusing on the analysis of key regulatory and structural genes involved in fibre biogenesis [12,13].

Jute (Corchorus sp.) covers about $80 \%$ of worldwide bast fibre production [12]. Among more than 100 of Corchorus species in the Malvaceae family, only Corchorus olitorius and Corchorus capsularis are commercially cultivated [12,14]. Lignocellulosic bast fibres are extracted from Corchorus capsularis for commercial purposes in the different industrial uses and textile sectors $[15,16]$. Usually jute fibre is composed of $61 \%$ cellulose, $15.9 \%$ hemicelluloses and $13.5 \%$ lignin [17], but in some cases it could contains as high as 15-22 \% of lignin [18]. The high content of lignin gives a unique xylan-type fibre properties of jute fibres which are distinguished from other gelatinous-type bast fibres of flax, hemp and ramie [19]. Jute fibre lignin seems the polymerization of three hydroxycinnamyl alcohols (monolignols), viz., p-coumaryl alcohol, coniferyl alcohol and sinapyl alcohol resulting in p-hydroxyphenyl, guaiacyl and syringyl units respectively [20]. However, this high level of lignin content causes several complexities in the formation of jute fibre and its valued product processing. For examples, photo-yellowing of jute products could be happened due to the $\alpha$-carbonyl group of the lignin structure which reacts with UV radiation. Besides, high lignin content also cause complexity in jute fibre separation as well 
as maintaining standard quality [21]. The above mentioned features has made the jute fibres less suitable for making divers valued finer fabrics and other standard products, and it mostly happens in the fibres from Corchorus capsularis. So, the development of low-lignin fibres has become a priority needs in jute industries as well as global market [15, 22].

Different studies reported several metabolic pathways as well as genes involved in the key processes of fibres formation [23,24]. But, there are yet limited studies in the molecular basis and regulatory process of lignin biosynthesis in xylan type bast fibres [25]. However, the availability of genomic data and comparative genome based analysis could allow the study of gene regulation and molecular interaction of different pathways involved in complex fibre formation process. MicroRNAs (miRNAs), small regulatory RNAs consisting of about 18-22 nucleotides could play an significant roles in different cellular functions in plants and animals [26]. It was found that miRNA might regulate gene expression at the different stages of posttranscriptional levels by interacting to specific targets for initiating mRNA inhibition or cleavage of mRNA translation [27,28]. Though, there are enormous possibilities to work with miRNA for controlling any specific biological process but still limited number of miRNAs has been identified in plants by experimental and computational approaches [29,30]. As miRNAs are highly evolutionarily conserved in the plant and animal kingdom, and that is why the nature of evolutionary conservation in the miRNAs allows an effective approach to the identification and characterization of newly conserved miRNAs using comparative genomics approach $[30,31,32,33]$.

Though the plethora of economic importance in the view of trading and commercial purposes, there has been no report on miRNAs in Corchorus capsularis. In this study, we employed an EST based homology search to identify miRNAs in jute using currently available 826 expressed sequence tags (ESTs) from the NCBI Genbank database. To avoid the difficulties of searching from genomic sequence surveys or unavailability of whole genome sequences, EST based miRNA identification by using specialized software has already been accepted successfully over the other approaches $[34,35,36,37,38]$. The present study was employed with the Identification and Characterization of conserved microRNAs in the genome of fibre biogenesis crop jute by using EST based comparative genomics approach. 


\section{Methods}

\subsection{Acquisition of EST Sequences and Reference miRNAs}

The available EST sequences of Corchorus capsularis were retrieved from the recently deposited genome (GenBank assembly accessionGCA_001974805.1) in the GenBank databases of $\operatorname{NCBI}(\underline{h t t p}: / / w w w . n c b i . n l m . n i h . g o v /)$ [12,39]. Moreover, to search potential miRNAs in $C$. capsularis, all previously known mature miRNA sequences of plant dicotyledons were extracted from miRBase database (http://www.mirbase.org/). These miRNAs were employed as the reference set with the retrieved ESTs of $C$. capsularis genome for identifying conserved miRNAs family in Jute. To avoid redundant or overlapping of miRNAs and ESTs, the repeated sequences of miRNAs and ESTs were removed by CD-HIT [40] and only the single ones were retained for further study.

\subsection{Search for potential miRNAs in the jute genome}

The reference miRNAs retrieved from miRBase were used as the query templates for homology search against the ESTs of Corchorus capsularis by using BLASTn of NCBI database (https://blast.ncbi.nlm.nih.gov/Blast.cgi) considering all default parameters. Only the top EST hit for each miRNA search was taken. Again, all of ESTs from BALSTn search were screened by CD-HIT for redundancy check.

\subsection{Screening for the non-coding miRNA candidates}

As the miRNAs are non-protein coding genes, the precursor miRNAs should also be non-protein coding. After redundancy check, the top hits from BLASTn were subjected to BLASTx (https://blast.ncbi.nlm.nih.gov/Blast.cgi) analysis for removing the protein-coding sequence. A number of EST sequences were found that were non protein coding. These miRNA candidates 
were then used for further screening to identify pre-miRNA by evaluating the miRNA precursor prediction properties [41].

\subsection{Identification of Novel miRNAs with Reported Criteria}

The different criteria were used to screen precursor miRNAs based on statistical comparative genomics approaches reported by Zhang et al., 2006 [42], which had already been adopted in many ESTs targeted miRNAs identification and characterization studies [43,44,45]. Here, only candidate ESTs sequences adopted the following criteria were prioritized as considerable miRNAs in $C$. capsularis: (1) not more than 3 mismatches were allowed in the putative miRNAS with all previously known plant miRNAs; (2) the length of predicted mature miRNAs should be in the range of 18 nucleotides; (3) pre-miRNA sequence must fold into an appropriate hairpin secondary structure and mature miRNA should be located in one arm of the hairpin stem-loop secondary structure; (4) the mature miRNAs should allow less than 3 mismatches with the opposite miRNA strand in the other arm; (5) A+U content of pre-miRNA must be in range of $30 \%$ to $70 \%$; and (6) the secondary structure of mature miRNAs must have lower minimal (highly negative) folding free energy (MFE) and minimal free energy index (MFEI) value $[46,47,48]$.

\subsection{Prediction of pre-miRNA and Hair-loop Secondary Structure of mature miRNAs}

The ESTs for putative miRNA prediction were subjected to mirEval (https://tools4mirs.org/) for determining the pre-miRN candidates [49]. The minimal length of the pre-miRNA was set as 85 nucleotide and these precursor sequences of potential miRNA homologs were assessed for secondary structures prediction using the Zuker folding algorithm [50] in the Mfold web server (http://unafold.rna.albany.edu/?q=mfold). As the predicted secondary structure should have the higher minimal negative value of minimal folding free energy index (MFEI) and minimal folding free energy (MFE), only the best fitted pre-miRNA candidates were obtained considering all parameters. The MFEI was calculated using the following equation;

Adjusted MFE (AMFE) represented the MFE of 100 nucleotides. 
$\mathrm{AMFE}=(\mathrm{MFE} \div$ length of RNA sequence $) * 100$

$\mathrm{MFEI}=\mathrm{AMFE} /(\mathrm{G}+\mathrm{C}) \%$

MFEI $=[($ MFE/length of the RNA sequence $) \times 100] /(\mathrm{G}+\mathrm{C}) \%$

\subsection{Nomenclature and family annotation of predicted microRNAs}

The putative miRNAs were used as query sequence for local blast in miRBase to reconfirm the family of the putative mature miRNAs. The predicted microRNAs were named by a nomenclature followed by miRBase [51]. Sequence alignment of homologous members of predicted miRNA family was investigated in the miRBase search output and rechecked by Clustal Omega [52,53]. The percentage of each nucleotide base of putative mature miRNAs and their respective homologue miRNAs from miRBase were also calculated and analyzed.

\subsection{Prediction and functional analysis of putative miRNA targets}

Due to the unavailability of $C$. capsularis resources regarding miRNA targeted genes, Arabidopsis was considered as the reference organism for prediction and functional annotation of the newly identified mature miRNAs in jute genome. The predicted mature miRNAs were employed as query against the $A$. thaliana by using psRNATarget database (http://plantgrn.noble.org/psRNATarget/) with following parameters: (1) maximum expectation value should be 5 ; (2) complementarity scoring (HSP) size should be kept within the length of 18; (2) target sites' multiplicity must be allowed to 2; (3) range of central mismatch for translational inhibition should be in the range of 10-11 nucleotide; (4) highest level of mismatches at the complementary site 4 except any gaps. The psRNATarget ensures reverse complementary matching between targets transcripts and respective miRNAs, leading to the target site accessibility by calculating unpaired energy (UPE) needed for beginning the secondary structure around the miRNA target site [54]. The schematic outline of the total methodology was illustrated in Figure 1.

\section{Results}




\subsection{Search for potential miRNAs in genome of $C$. capsularis}

To identify and characterize the conserved microRNA of $C$. capsularis, a comprehensive EST based study was employed. There were different in silico steps where a huge volume of preliminary ESTs of $C$. capsularis were screened to finalize the putative miRNAs with specific gene targets involved in the biological process of jute alongside biogenesis of fibres. The summery of details process with the numerical data was described in the Table 1 . The previously known mature miRNAs under the dicotyledons, belonging to twenty plants families (Amaranthaceae, Araliaceae, Asteraceae, Cucurbitaceae, Euphorbiaceae, Fabaceae, Caricaceae, Lamiales, Linaceae, Malvaceae, Myrtaceae, Paeoniaceae, Brassicaceae, Ranunculaceae, Rhizophoraceae, Rosaceae, Rutaceae Salicaceae, Solanaceae, Vitaceae) were extracted from the microRNA database. In this approach, a total of 6386 of plant miRNA (Supplementary File 1) were retrieved. About 826 ESTs of Corchorus capsularis (Supplementary File 2) were retrieved from the GenBank databases of NCBI. Redundant miRNAs and ESTs were removed, and only the unique ones were retained. About 3036 redundant miRNA sequences were removed, retaining 3350 miRNAs containing no repeated sequences were kept for the further investigation (Supplementary File 3). On the other hand, 763 non-redundant ESTs of jute were kept from 826 ESTs (Supplementary File 4). Here, 763 non-redundant Jute ESTs were searched against 3350 non-redundant mature miRNA sequences of all dicotyledons. After the removal of redundancy by CDHIT, around $621 \mathrm{ESTs}$ were selected as potential miRNA sequences for Corchorus capsularis (Supplementary File 5). Moreover, It had been found that around 36 ESTs were noncoding which could be the potential candidates of miRNA homologs (Supplementary File 6).

\subsection{Prediction of pre-miRNAs and Hair-loop Secondary Structure of mature miRNAs}

About the 36 non-coding ESTs were investigated to identify the potential miRNA precursors by evaluating the miRNA precursor prediction properties using mirEval (https://tools4mirs.org/). The different preset criteria were strictly followed in each steps to screen out the putative miRNAs in Corchorus capsularis. Here, five ESTs were considered as pre-miRNA by careful evaluation ( Table 2 and Supplementary Table 1), while the other 31 ESTs (Supplementary File 7) were filtered out as they failed to fulfill the criteria mentioned in the Materials and Methods 
section. The final five precursor sequences of potential miRNAs were assessed for confirming their ability to form secondary structures using the Zuker folding algorithm of MFOLD software (Figure 2). It was observed that all five pre-miRNAs were capable of folding themselves into an appropriate hairpin structure as predicted by mirEval. There was also minimal loop involvement in the hairpin structures of the miRNAs. The four mature miRNAs were incorporated in only one loop of their respective hairpin structure while the other one was in a single-arm without involving any loop (Figure 2). The minimal folding free energy (MFE, $d G$ in $\mathrm{kcal} / \mathrm{mol}$ ) of all the pre-miRNAs were ranged between -59.60 and -14.90 while the percentage of $\mathrm{A}+\mathrm{U}$ contents of the precursors were ranged between $55 \%$ and $65 \%$ (Table 2).

\subsection{Nomenclature and family annotation of predicted microRNAs}

The miRBase database was used to search out and address the microRNAs family of the predicted five putative miRNAs. It had been found that the five miRNAs of jute belong to five different miRNA families (miR1536, miR9567-3p, miR4391, miR11300 and miR8689) and the nomenclature of the predicted miRNAs were done as cca-miR1536, cca-miR9567-3p, ccamiR4391, cca-miR11300, and cca-miR8689. Sequence alignment of putative miRNAs of jute genome and its homologous member from miRBase were visualized in Figure 3. The average each nucleotide base percentage of cca-miR1536, cca-miR9567-3p, cca-miR4391, ccamiR11300, and cca-miR8689 were calculated, and compared with the each nucleotide base percentage of gma-miR1536, bra-miR9567-3p, gma-miR4391, fve-miR11300 and gra-miR8689 respectively. It had been investigated that the percentage of adenine, uracil, guanine and cytosine of both putative mature miRNA of jute and their correspondence reference miRNA were almost in the similar quantity. In addition, the adenine percentage was found higher in the miRNA family of miR9567-3p and miR4391 for whereas other two families, namely, miR1536 and miR8689 showed higher percentages in case of uracil and guanine respectively (Figure 4).

\subsection{Prediction and functional analysis of putative miRNA targets}

The five novel jute miRNAs were found to be involved with a total of 1052 targets as predicted by the psRNATarget (Supplementary Table 2). Among the around 1052 gene targets, 147 was found to be uncharacterized. All of the gene targets were cross checked where four gene targets were found as the common target for the five putative miRNAs, and those targets were also 
highly abundant in the target pool ('Leucine-rich repeat family protein; 13 times', 'Transposable element gene; 87 times', 'Protein kinase superfamily protein; 17 times', 'Pentatricopeptide repeat superfamily protein; 9 times'). Comprehensive literature studies were employed to find out the involvement of predicted gene targets in different biological process. There were few gene targets which were found to be directly or indirectly involved with the lignin biosynthesis and secondary wall biogenesis (Table 3) [55-68]. The functions of the common gene targets were also described in the Table 3 [69-76]. Moreover, there were three gene targets (alpha/betaHydrolases superfamily protein, RING/U-box superfamily protein and P-loop containing nucleoside triphosphate hydrolases superfamily protein coding genes) were found to be involved with four putative miRNAs of jute (Supplementary Table 2).

\section{Discussion}

Identification of conserved microRNA in the genome of C. capsularis may have significant roles in the improvement of fibres quality including its mass production. Though xylan type bast fibres are traditionally used in the low quality household products because of its lower smoothness and higher percentage of lignin compounds, but now jute products are being emphasized for the sustainable application for its eco-friendly nature[77,78,79,80]. Hence, lignin biogenesis pathways and other molecular basis of fibres formation are now getting more importance for its commercial and economic perspective $[81,82,83]$. The regulation of lignin biosynthesis leading to fibres formation could initiate the lower percentage of lignin compound in the jute fibres which is the prerequisite for high quality fibres product. MicroRNAs are now being prioritized in the molecular research for their diverse cellular applications from the post-transcriptional regulation to gene expression [84,85]. Although miRNAs have been extensively studied for several years in many plant species $[86,87,88]$, but no systematic study has been performed on the $C$. capsularis. The present study was carried out to identify the putative conserved microRNA candidates from the genome of $C$. capsularis by employing different screening process. Though there are several computational approaches for identifying the miRNAs in the higher plants, animals or even in the microorganisms, but EST based miRNA search has been reported more convenient than other methods $[89,90]$. ESTs, partially transcribed gene sequences could be used to detect the presence and expression of potential miRNAs in the higher plants 
$[91,92]$. Plant miRNAs are found to be conserved in the deferent evolutionary convergent species [93]. In the present study, previously known mature miRNAs of dicotyledons were used to conduct homology based search for identifying the putative miRNA homologs of $C$. capsularis in the available ESTs of jute genome. Though, few previous miRNA studies of higher plants used only the miRNAs of Arabidopsis thaliana for their homology search [94,95], but present study considered around 3350 non-redundant mature miRNAs of dicotyledons plants for enhancing the strength of broad spectrum homology search for conserved miRNAs in the jute genome.

Retrieved mature miRNAs of dicotyledons were allowed to homology search with 763 nonredundant ESTs of $C$. capsularis where 621 ESTs were identified for the further screening process. Non-coding ESTs were prioritized for being the putative miRNAs candidates [96,97,98] and only 36 non-coding ESTs were finalized in the present study. Different criteria were set up for screening the ESTs in order to identify the putative miRNAs of jute $[99,100]$. Though it had been reported that one miRNA exists per 10,000 ESTs in plants [101,102], but five miRNAs have been characterized in $C$. capsularis genome through scrutinizing a series of screening processes from initial 826 ESTs. The putative miRNAs were found with 18 nucleotide length which are also observed in the other studies [103,104]. The pre-miRNA were checked for the ability of folding into an appropriate hairpin secondary structure and mature miRNA should be placed in one arm of the hairpin structure (Figure 2). Minimal free energy index (MFEI) indicates the probable miRNA (average MFEI $=-0.65$ ) candidates with respect to other RNAs such as tRNAs (MFEI = -0.64) and rRNAs (MFEI = -0.59) $[105,106,107,108]$. The MFEI value of the newly identified five putative miRNAs of jute were found within the average range $(-0.49$, $-0.58,-0.6,-0.73$, and -1.56$)$. Here, $(\mathrm{A}+\mathrm{U})$ content of pre-miRNA were found between the range of $55 \%$ to $61 \%$, which was also observed in the other higher plants miRNAs [109,110,111]. Five conserved miRNA families (miR1536, miR9567-3p, miR4391, miR11300 and miR8689) were found in the jute genome which were also reported in the different plant families [112,113,114,115] and the predictive putative miRNAs were entitled as cca-miR1536, ccamiR9567-3p, cca-miR4391, cca-miR11300, and cca-miR8689. Multiple sequence alignment and comparative nucleotide composition studies exhibited that the putative miRNAs of jute were highly conserved in the other organisms which supported the evolutionary convergent relationships among the higher plant species [116,117,118]. 
In addition, a total of 1052 genes were identified which could be inhibited by the predicted mature miRNAs of jute. Among this huge gene pool, there were five genes which were somehow involved in the lignin biosynthesis or secondary cell wall formation process. 'NAC Domain Containing Protein', 'WRKY DNA binding protein', '3-dehydroquinate synthase', 'S-adenosylL-Met-dependent methyl transferase' and 'Vascular-related NAC-Domain' coding genes associated with the putative miRNA of jute were studied exclusively for their important roles in the lignin biosynthesis or secondary cell wall formation. The study revealed that cca-miR4391 and cca-miR11300 might inhibit the 'NAC Domain Containing Protein' whereas cca-miR1536, cca-miR4391 and cca-miR8689 might cleave the ' $S$-adenosyl-1-Met-dependent methyl transferase'.NAC are functionally redundant, being sufficient for all vessel secondary cell wall formation in fibres and vessels. Secondary cell wall formation associated NAC protein and its functional homologues are master switches that turn on a subset of transcription factors which also directly activate the expression of SCW biosynthetic genes [55,56]. The diverse variety of 'S-adenosyl-1-Met-dependent methyl transferase' has been observed in the plant. During the biogenesis of numerous plant secondary compounds alongside lignin molecules, ' $S$-adenosyl-1Met-dependent methyl transferase' usually act on Phe-derived substrates. This enzymes has also been reported for its contribution in the synthesis of phytoestrogens, allelochemicals, flower pigments, antimicrobial compounds and isoflavonoid [57,58,59]. 'WRKY DNA binding protein' could be inhibited by the predicted cca-miR9567 and cca-miR8689 of Corchorus capsularis, and this protein could regulate the phenylpropanoid pathway and contribute in the biosynthesis of important pharmaceutical, aromatherapy and biofuel $[60,61,62]$. WRKYs are exclusively needed for proper expression of genes in the lignin biosynthetic pathway, and these are also found to be involved in the synthesis of phytohormones, phytoalexins, and other defense-related chemicals $[63,64,65]$. Again, the putative cca-miR1536 and cca-miR9567 were found to inhibit the ' 3 dehydroquinate synthase' and 'S-adenosyl-L-Met-dependent methyl transferase' where '3dehydroquinate synthase' had significance contribution in the shikimate and aromatic amino acid biosynthetic pathways [66]. In addition, 'Vascular-related NAC-Domain (VND)' could be inhibited by the predicted cca-miR9567-3p. In Arabidopsis, secondary wall biosynthesis in the xylem conducting cells, vessels, has also been shown to be regulated by VND genes [67]. The expression of VND4 gene was found mostly in the vessels and it was able to turn on transcription 
factors involved in the expression of secondary wall-associated functions and programmed cell death. VND4 was also found to prevent the the secondary wall defects in the fibers [68]. Though lignin provides mechanical strength to save fibres from biological or chemical degradation, it assumes to easy separation of lignin during fibres process for making quality products [119]. Here, the predicted miRNAs were found to be potent to target essential genes involved in the lignin or secondary wall synthesis alongside with different cellular process. The miRNA targeted regulation over the gene expression has already been reported in different plant species $[120,121,122]$, hence, the putative miRNA of jute might exhibit regulatory roles over the important cellular expression through in vivo and in vitro validation.

\section{Conclusion}

As the screening and characterization of mature miRNAs has yet to be investigated in $C$. capsularis, it seems the predicted mature miRNAs and target genes might be larger and these are needed to be studied for complete understanding of miRNA derived regulation over the production of high quality fibres. The current study concluded with the suggestion of putative miRNAs in the jute genome with their correspondent gene targets, and also reflected some of the key regulatory proteins involved in the lignin biosynthesis that might be controlled by miRNA dependent cellular actions.

\section{Acknowledgements}

Authors would like to acknowledge the Faculty of Biotechnology and Genetic Engineering, Sylhet Agricultural University for the technical support of the project.

\section{Funding information}

This research did not receive any specific grant from funding agencies in the public, commercial, or not-for-profit sectors.

\section{Conflict of interest}

Authors declare that they have no conflict of interests. 


\section{References}

1. S. Maity, K. Singha, D.P. Gon, P. Paul, M. Singha, A review on jute nonwovens: manufacturing, properties and applications, Int. J. Text. Sci. 1 (2012) 36-43.

2. M.S. Sharif, M.S. Khan, A.F. Tayab, Energy Efficiency Improvement Scopes Analysis in the Jute Processing Industry of Bangladesh, Eur. J. Adv. Eng. Technol. 3 (2016) 5-10.

3. A. Uygur, The Future of Organic Fibres, Eur. J. Sustain. Dev. Res. 2 (2017) 164-72.

4. R. Blackburn, Biodegradable and sustainable fibres, first ed., Elsevier, USA, 2005.

5. J.E. van-Dam. Natural fibres and the environment: environmental benefits of natural fibre production and use, InProceedings of the Symposium on Natural Fibres: Common fund for commodities, (2008) 3-17.

6. M.S. Islam, S.K. Ahmed, The impacts of jute on environment: An analytical review of Bangladesh, J. Environ. Earth Sci. 5 (2012) 24-31.

7. Statistical Bulletin-2014, Food and Agriculture Organization, United Nations, 2014.

8. V.K. Thakur, M.K. Thakur, R.K. Gupta, Review: Raw Natural Fiber-Based Polymer Composites, Int. J. Polym. Anal. Charact. 19 (2014) 256-271.

9. J.A. Khan, M.A. Khan, R. Islam, A. Gafur, Mechanical, Thermal and interfacial properties of jute fabric-reinforced polypropylene composites: effect of potassium dichromate, Mater. Sci. Appl. 1 (2010) 350-357.

10. M. Jawaid, H.A. Khalil, A.A. Bakar, Mechanical performance of oil palm empty fruit bunches/jute fibres reinforced epoxy hybrid composites, Mater. Sci. Eng. 527 (201) 7944-7949.

11. H. Li, M.M. Sain, High stiffness natural fiber-reinforced hybrid polypropylene composites, Polym. Plast. Tech. Eng. 42 (2003) 853-862.

12. M.S. Islam, J.A. Saito, E.M. Emdad, B. Ahmed, M.M. Islam, A. Halim, Q.M. Hossen, M.Z. Hossain, R. Ahmed, M.S. Hossain, S.M. Kabir, Comparative genomics of two jute species and insight into fibre biogenesis, Nat. Plants 3 (2017) 1-7. 
13. L. Zhang, Y. Xu, X. Zhang, X. Ma, L. Zhang, Z. Liao, Q. Zhang, X. Wan, Y. Cheng, Zhang, D. Li, The genome of kenaf (Hibiscus cannabinus L.) provides insights into bastfibre and leaf shape biogenesis, Plant Biotechnol. J. (2020) 1-14.

14. T. Furumoto, R. Wang, K. Kokazaki, F. Afm, M.l. Ali, A. Kondo, H. Fukui, Antitumor promoters in leaves of jute (Corchorus capsularis and Corchorus olitorius), Food Sci. Technol. Res. 8 (2002) 239-43.

15. D. A. Baker, T. G. Rials, Recent advances in low-cost carbon fiber manufacture from lignin, J. Appl. Polym. Sci. 130 (2013) 713-28.

16. B.C. Kundu, Anatomy of jute stem with special reference to cambial activity and distribution of fibres in relation to leaf-trace system, J. Royal. Asiatic Soc. Bengal Sci. 10 (1944) 27-52.

17. D. Sarkar, M.K. Sinha, A. Kundu, C.S. Kar, A. Saha, L.L. Kharbikar, B.S. Mahapatra, Why is ramie the strongest yet stiffest of bast fibres?, Curr. Sci. 98 (2010) 1570-1572.

18. G. Sengupta, P. Palit, Characterization of a lignified secondary phloem fibre-deficient mutant of jute (Corchoruscapsularis), Ann. Bot. 93 (2004) 211-220.

19. J.H. Meshram, P. Palit, On the role of cell wall lignin in determining the fineness of jute fibre, Acta Physiol. Plant 35 (2013) 1565-1578.

20. R. Vanholme, B. Demedts, K. Morreel, J. Ralph, W. Boerjan, Lignin biosynthesis and structure, Plant Physiol. 153 (2010) 895-905.

21. J.C. Del Rio, J. Rencoret, G. Matques, J. Li, G. Gellerstedt, J. Jiménez-Barbero, A.T. Martínez, A. Gutiérrez, Structural characterization of the lignin from jute (Corchoruscapsularis) fibers, J. Agric. Food Chem. 57 (2009) 10271-10281.

22. S.B. Choudhary, I. Chowdhury, R.K. Singh, S.P. Pandey, H.K. Sharma, A.A. Kumar, P.G. Karmakar, N. Kumari, J. Souframanien, S.J. Jambhulkar, Morphological, histobiochemical and molecular characterisation of low lignin phloem fibre (llpf) mutant of dark jute (Corchorusolitorius L.), Appl. Biochem. Biotechnol. 183 (2017) 980-992.

23. H.C. van den Broeck, C. Maliepaard, M.J.M. Ebskam, M.A.J. Toonen, A.J. Koops, Differential expression of genes involved in $\mathrm{C} 1$ metabolism and lignin biosynthesis in wooden core and bast tissues of fibre hemp (Cannabis sativa L.), Plant Sci. 174 (2008) $205-220$. 
24. Z. Sun, X. Wang, Z. Liu, Q. Gu, Y. Zhang, Z. Li, H. Ke, J. Yang, J. Wu, L. Wu, G. Zhang, Genome-wide association study discovered genetic variation and candidate genes of fibre quality traits in Gossypium hirsutum L. Plant Biotechnol. J. (2017) 982-96.

25. P. Chiaiese, G. Ruotolo, A. Di Matteo, A. De Santo Virzo, A. De Marco, E. Filippone, Cloning and expression analysis of kenaf (Hibiscus cannabinus L.) major lignin and cellulose biosynthesis gene sequences and polymer quantification during plant development, Ind. Crops Prod. 34 (2011) 1072-1078.

26. V. Ambros, X.M. Chen, The regulation of genes and genomes by small RNAs, Dev. 134 (2007) 1635-1641.

27. B. Zhang, X. Pan, G.P. Cobb, T.A. Anderson, Plant microRNA: a small regulatory molecule with big impact, Dev. Biol. 289 (2006) 3-16.

28. K.A. Khade, M. Panigrahi, S.F. Ahmad, A. Chauhan, P. Kumar, B. Bhushan, Cloning and characterization of Bubaline mammary miRNAs: An in silico approach, Mol. Biol. Rep. 46 (2019) 1257-1262.

29. A. Akter, M.M. Islam, S.I. Mondal, Z. Mahmud, N.A. Jewel, S. Ferdous, M.M. Rahman, Computational identification of miRNA and targets from expressed sequence tags of coffee (Coffeaarabica), Saudi J. Biol. Sci. 21 (2014) 3-12.

30. H. Gadhavi, M. Patel, N. Mangukia, K. Shah, K. Bhadresha, S.K. Patel, R.M. Rawal, H.A. Pandya, Transcriptome-wide miRNA identification of Bacopamonnieri: a cross-kingdom approach, Plant Signaling Behav. 15 (2020) 1699265.

31. M. Farooq, S. Mansoor, H. Guo, I. Amin, P.W. Chee, M.K. Azim, A.H. Paterson, Identification and characterization of miRNA transcriptome in Asiatic cotton (Gossypiumarboreum) using high throughput sequencing,Front. Plant Sci. 8 (2017) 969.

32. J.S. Curcio, M.P. Batista, J.D.Paccez, E.Novaes, C.M.Soares, In silico characterization of microRNAs-like sequences in the genome of Paracoccidioidesbrasiliensis, Genet. Mol. Biol. 42 (2019) 95-107.

33. S. Marakli. In silico determination of transposon-derived miRNAs and targets in Aegilops species,J. Biomol. Struct. Dyn. 28 (2019) 1-2.

34. M. Vohra, A.R. Sharma, B. Paul, M.K. Bhat, K. Satyamoorthy, P.S. Rai, In silico characterization of functional single nucleotide polymorphisms of folate pathway genes. Ann. Hum. Genet. 82 (2018) 186-199. 
35. W. Jike, G. Sablok, G. Bertorelle, M. Li, C. Varotto,In silico identification and characterization of a diverse subset of conserved microRNAs in bioenergy crop Arundodonax L, Sci. Rep. 8 (2018) 1-3.

36. Z. Zinati, R. Shamloo-Dashtpagerdi, A. Behpouri,In silico identification of miRNAs and their target genes and analysis of gene co-expression network in saffron (Crocus sativus) stigma, Mol. Biol. Res. Commun. 5 (2016) 233.

37. R. Ellango, R. Asokan, V.V. Ramamurthy,Insilco prediction and characterization of microRNAs from Oncopeltusfasciatus (Hemiptera: Lygaeidae) genome, Appl. Biochem. Biotechnol.179 (2016) 1393-1403.

38. J. Singh, J. Nagaraju,In silico prediction and characterization of microRNAs from red flour beetle (Triboliumcastaneum), Insect Mol. Biol. 17 (2008) 427-436.

39. N.R. Coordinators, Database resources of the national center for biotechnology information, Nucleic Acids Res. 4 (2016) D7.

40. L. Fu, B. Niu, Z. Zhu, S. Wu, W. Li,CD-HIT: accelerated for clustering the nextgeneration sequencing data, Bioinformatics28 (2012) 3150-3152.

41. Z. Qin, C. Li,L. Mao, L. Wu, Novel insights from non-conserved microRNAs in plants, Front. Plant Sci. 5 (2014) 1-10.

42. B.H. Zhang, X.P. Pan, S.B. Cox,G.P. Cobb,T.A. Anderson, Evidence that miRNAs are different from other RNAs, Cell. Mol. Life Sci. 63 (2006) 246-254.

43. Y. Kurihara, Y. Watanabe, From The Cover: Arabidopsis micro-RNA biogenesis through Dicer-like 1 protein functions, Proc. Natl. Acad. Sci. 101 (2004) 12753-12758.

44. C. Muvva, L. Tewari, K. Aruna, P. Ranjit, In silico identification of miRNAs and their targets from the expressed sequence tags of Raphanus sativus, Bioinformation. 8 (2012) 98.

45. X.J. Wang, J.L. Reyes, N.H. Chua, T. Gaasterland, Prediction and identification of Arabidopsis thaliana microRNAs and their mRNA targets, Genome Biol. 5 (2004) 65.

46. N. Singh, S. Srivastava, A. Sharma, Identification and analysis of miRNAs and their targets in ginger using bioinformatics approach, Gene 575 (2016) 570-576.

47. P. Prakash, D. Ghosliya, V. Gupta, Identification of conserved and novel microRNAs in Catharanthusroseus by deep sequencing and computational prediction of their potential targets, Gene 554 (2015) 181-195. 
48. J.H. Xu, F. Li, Q.F. Sun, Identification of microRNA precursors with support vector machine and string kernel, Genom. Proteom. Bioinf. 6 (2008) 121-128.

49. D. Gao, R. Middleton, J.E. Rasko, W. Ritchie, miREval 2.0: a web tool for simple microRNA prediction in genome sequences, Bioinformatics 29(2013) 3225-3226.

50. M. Zuker, Mfold web server for nucleic acid folding and hybridization prediction, Nucleic Acids Res. 31(2003) 3406-3415.

51. S. Griffiths-Jones, R.J. Grocock, S. Van Dongen, A. Bateman, A.J. Enright,miRBase: microRNA sequences, targets and gene nomenclature, Nucleic Acids Res. 34 (2006) 140144.

52. F. Sievers, D.G. Higgins, Clustal omega, Curr. Protoc. Bioinformatics. (2014) 3-13.

53. F. Sievers, A. Wilm, D. Dineen, T.J. Gibson, K. Karplus, W. Li, R. Lopez, H. McWilliam, M. Remmert, J. Söding, J.D. Thompson, Fast, scalable generation of high-quality protein multiple sequence alignments using Clustal Omega, Mol. Syst. Biol. (2011) 1-7.

54. X. Dai, P.X. Zhao, psRNATarget: a plant small RNA target analysis server, Nucleic Acids Res. 39 (2011) 155-159.

55. M. Kubo, M. Udagawa, N. Nishikubo, G. Horiguchi, M. Yamaguchi, J. Ito, T. Mimura, H. Fukuda, T. Demura, Transcription switches for protoxylem and metaxylem vessel formation, Genes Dev. 19 (2005) 1855-1860.

56. Y. Yang, C.G. Yoo, W. Rottmann, K.A. Winkeler, C.M. Collins, L.E. Gunter, S.S. Jawdy, X. Yang, Y. Pu, A.J. Ragauskas, G.A. Tuskan, PdWND3A, a wood-associated NAC domain-containing protein, affects lignin biosynthesis and composition in Populus, BMC Plant Biol. 19 (2019) 1-2.

57. L. Li, J.L. Popko, X.H. Zhang, K. Osakabe, C.J. Tsai, C.P. Joshi, V.L. Chiang, A novel multifunctional O-methyltransferase implicated in a dual methylation pathway associated with lignin biosynthesis in loblolly pine, Proc. Natl. Acad. Sci. 94 (1997) 5461-5466.

58. J. Van Doorsselaere, M. Baucher, E. Chognot, B. Chabbert, M.T. Tollier, M. Petit-Conil, J.C. Leplé, G. Pilate, D. Cornu, B. Monties, M. Van Montagu, A novel lignin in poplar trees with a reduced caffeic acid/5-hydroxyferulic acid O-methyltransferase activity, Plant J. 8 (1995) 855-864. 
59. N.A. Eckardt, Probing the mysteries of lignin biosynthesis: the crystal structure of caffeic acid/5-hydroxyferulic acid 3/5-O-methyltransferase provides new insights, Plant Cell 14 (2002) 1185-1189.

60. M.A. Naoumkina, X. He, R.A. Dixon, Elicitor-induced transcription factors for metabolic reprogramming of secondary metabolism in Medicago truncatula, BMC Plant Biol. 8 (2008) 132.

61. H. Wang, U. Avci, J. Nakashima, M.G. Hahn, F. Chen, R.A. Dixon, Mutation of WRKY transcription factors initiates pith secondary wall formation and increases stem biomass in dicotyledonous plants, Proc. Natl. Acad. Sci. 107 (2010) 22338-22343.

62. P. Tripathi, R.C. Rabara, P.J. Rushton, A systems biology perspective on the role of WRKY transcription factors in drought responses in plants, Planta 239 (2014) 255-266.

63. M. Bakshi, R. Oelmüller, WRKY transcription factors: Jack of many trades in plants, Plant Signal Behav. 9 (2014) 27700.

64. X. Liang, X. Chen, C. Li, J. Fan, Z. Guo, Metabolic and transcriptional alternations for defense by interfering OsWRKY62 and OsWRKY76 transcriptions in rice, Sci. Rep. 7 (2017) 1-5.

65. S. Besseau, J. Li, E.T. Palva, WRKY54 and WRKY70 co-operate as negative regulators of leaf senescence in Arabidopsis thaliana, J. Exp. Bot. 63 (2012) 2667-2679.

66. A. Chakraborty, D. Sarkar, P. Satya, P.G. Karmakar, N.K. Singh, Pathways associated with lignin biosynthesis in lignomaniac jute fibres, Mol. Genet. Genomics 290 (2015) 1523-1542.

67. M. Yamaguchi, N. Mitsuda, M. Ohtani, M. Ohme-Takagi, K. Kato, T. Demura, VASCULAR-RELATED NAC-DOMAIN 7 directly regulates the expression of a broad range of genes for xylem vessel formation, Plant J. 66 (2011) 579-590.

68. J. Zhou, R. Zhong, Z.H. Ye, Arabidopsis NAC domain proteins, VND1 to VND5, are transcriptional regulators of secondary wall biosynthesis in vessels, PloS One 9 (2014) 105726.

69. S. Shanmugam, T. Palvannan, T.S. Kumar, A. Michael, Biological decolourization of textile and paper effluents by Pleurotus florida and Agaricus bisporus (White-rot basidiomycetes), World J. Microb. Biot. 21 (2005) 1149-1151. 
70. D.A. Cushing, N.R. Forsthoefel, D.R. Gestaut, D.M. Vernon, Arabidopsis emb175 and other ppr knockout mutants reveal essential roles for pentatricopeptide repeat (PPR) proteins in plant embryogenesis, Planta 221 (2005) 424-436.

71. J.L. Bennetzen, Transposable element contributions to plant gene and genome evolution, Plant Mol. Biol. 42 (2000) 251-269.

72. M. Sahebi, M.M. Hanafi, A.J. van Wijnen, D. Rice, M.Y. Rafii, P. Azizi, M. Osman, S. Taheri, M.F. Bakar, M.N. Isa, Y.M. Noor, Contribution of transposable elements in the plant's genome, Gene 665 (2018) 155-166.

73. J.M. Stone, J.C. Walker, Plant protein kinase families and signal transduction, Plant Physiol. 108 (1995) 451-457.

74. N.G. Halford, S.J. Hey, Snf1-related protein kinases (SnRKs) act within an intricate network that links metabolic and stress signalling in plants, Biochem. J. 419 (2009) 247259.

75. M.D. Lehti-Shiu, S.H. Shiu, Diversity, classification and function of the plant protein kinase superfamily, Philos. Trans. R. Soc. Lond. B. Biol. Sci. 367 (2012) 2619-2639.

76. A. Barkan, I. Small, Pentatricopeptide repeat proteins in plants, Annu. Rev. Plant Biol. 65 (2014) 415-442.

77. D.S. Bajwa, G. Pourhashem, A.H. Ullah, S.G. Bajwa, A concise review of current lignin production, applications, products and their environmental impact, Ind. Crops. Prod. 139 (2019) 111526.

78. A. Agrawal, N. Kaushik, S. Biswas, Derivatives and applications of lignin- An insight, The Sci. Tech. J. 1 (2014) 30-36.

79. F. Rosillo-Calle, P. de-Groot, S.L Hemstock, J. Woods, The Biomass Assessment Handbook, second ed., Routledge, United Kingdom, 2012.

80. H. Luo, M.M. Abu-Omar, Chemicals from lignin, Elsevier, (2017) 573-585.

81. Q. Liu, L. Luo, L. Zheng,Lignins: biosynthesis and biological functions in plants,Int. J. Mol. Sci. 19 (2018) 335.

82. N.N. Das, S.C. Das, A.S. Dutt, A. Roy, Lignin-xylan ester linkage in jute fiber (Corchorus capsularis), Carbohydr. Res. 94 (1981) 73-82. 
83. G. Zhang, Y. Zhang, J. Xu, X. Niu, J. Qi, A. Tao, L. Zhang, P. Fang, L. Lin, J. Su, The CCoAOMT1 gene from jute (Corchoruscapsularis L.) is involved in lignin biosynthesis in Arabidopsis thaliana, Gene 546(2014) 398-402.

84. M.C. Zakeel, M.I. Safeena, T. Komathy, In silico identification of microRNAs and their target genes in watermelon (Citrulluslanatus), Sci. Hortic. 252 (2019) 55-60.

85. A.M. Gurtan, P.A. Sharp, The role of miRNAs in regulating gene expression networks, J. Mol. Biol. 425 (2013) 3582-600.

86. P. Mohanpuria, N. Duhan, N.K. Sarao, M. Kaur, M. Kaur, In silico identification and validation of potential microRNAs in Kinnow Mandarin (Citrus reticulata Blanco), Interdiscip. Sci. 10 (2018) 762-770.

87. M.S. Iqbal, B. Jabbar, M.N. Sharif, Q. Ali, T. Husnain, I.A. Nasir. In silico MCMV silencing concludes potential host-derived miRNAs in maize, Front. Plant Sci. 8 (2017) 372.

88. J.S. Yumnam, M. Rai, W. Tyagi, In silico characterisation of novel rice transcripts differentially expressed in phosphorus dificient conditions suggests a role of these transcripts in multiple abiotic stresses, Acta Biol. Hung. 64 (2017) 398-411.

89. T.P. Frazier, F. Xie, A. Freistaedter, C.E. Burklew, B. Zhang, Identification and characterization of microRNAs and their target genes in tobacco (Nicotianatabacum), Planta 232 (2010) 1289-1308.

90. B.H. Zhang, X. Pan, E.J. Stellwag, Identification of soybean microRNAs and their targets, Planta 229 (2008) 161-182.

91. E. Bonnet, J. Wuyts, P. Rouze, Y.V. Peer, Evidence that microRNA precursors, unlike other non-coding RNAs, have lower folding free energies than random sequences, Bioinformatics 20 (2004) 2911-2917.

92. B.H. Zhang, X.P. Pan, G.P. Cobb, T.A. Anderson, Plant microRNA: a small regulatory molecule with big impact, Dev. Biol. 289 (2006) 3-16.

93. D.P. Bartel, MicroRNAs: genomics, biogenesis,mechanism, and function, Cell 116 (2004) 281-297.

94. D. Jin, Y. Wang, Y. Zhao, M. Chen, MicroRNAs and their cross-talks in plant development, J. Genet. Genomics. 40 (2013) 161-170. 
95. A. Pani, R.K. Mahapatra, N. Behera, P.K. Naik, Computational identification of sweet wormwood (Artemisia annua) microRNA and their mRNA targets, Genom. Proteom. Bioinf. 9 (2011) 200-210.

96. Y. Watanabe, M. Tomita, A. Kanai, Computational methods for microRNA target prediction, Method. Enzymol. 427 (2007) 65-86.

97. S. Asha, J. Nisha, E.V. Soniya, In silico characterisation and phylogenetic analysis of two evolutionarily conserved miRNAs (miR166 and miR171) from black pepper (Piper nigrum L.), Plant Mol. Biol. Rep. 31 (2013) 707-18.

98. T. Dezulian, M. Remmert, J.F. Palatnik, D. Weigel, D.H. Huson, Identification of plant microRNA homologs, Bioinformatics 22 (2006) 359-360.

99. B.H. Zhang, X.P. Pan, Q.L. Wang, G.P. Cobb, T.A. Anderson, Identification and characterization of new plant microRNAs using EST analysis, Cell Res. 15 (2005) 336360.

100. A.T. Vivek, In silico identification and characterization of microRNAs based on EST and GSS in orphan legume crop, Lens culinarismedik. (Lentil), Agri. Gene. 8 (2018) 45-56.

101.N.P. Vishwakarma, V.J. Jadeja, Identification of miRNA encoded by Jatropha curcas from EST and GSS, Plant Signal Behav. 8 (2013) 23152.

102.S. Sahu, A. Khushwaha, R.Dixit, Computational identification of miRNAs in medicinal plant Senecio vulgaris (Groundsel), Bioinformation 7 (2011) 375.

103.S.M. Karani, A. Bahari, A. Eskandari, D. Koolivand, In Silico identification of miRNA encoded by Heteroderaglycines based on database of EST, Iraninan Plant Protection Congress (2016) 233.

104.R. Sunkar, G. Jagadeeswaran, In silico identification of conserved microRNAs in large number of diverse plant species, BMC Plant Biol. 8 (2008) 37.

105. A. Das, S. Chaudhury, M.C. Kalita, T.K. Mondal, In silico identification, characterization and expression analysis of miRNAs in Cannabis sativa, Plant Gene. 2 (2015) 17-24.

106.Z. Yin, C. Li, X. Han, F. Shen, Identification of conserved microRNAs and their target genes in tomato (Lycopersiconesculentum), Gene 414 (2008) 60-66.

107.B. Zhang, X. Pan, E.J. Stellwag, Identification of soybean microRNAs and their targets, Planta 229 (2008) 161-182. 
108.Y. Zhang, X. Zhu, X. Chen, C. Song, Z. Zou, Y. Wang, M. Wang, W. Fang, X. Li, Identification and characterization of cold-responsive microRNAs in tea plant (Camellia sinensis) and their targets using high-throughput sequencing and degradome analysis, BMC Plant Biol. 14 (2014) 271.

109.A. Pani, R.K. Mahapatra, Computational identification of microRNAs and their targets in Catharanthusroseus expressed sequence tags, Genom. Data 1 (2013) 2-6.

110.M. Din, M.Y. Barozai, I.A. Baloch, Identification and functional analysis of new conserved microRNAs and their targets in potato (Solanum tuberosum L.), Turk. J. Bot. 38 (2014) 1199-1213.

111.M.Y. Barozai, M. Din, I.A. Baloch, Structural and functional based identification of the bean (Phaseolus) microRNAs and their targets from expressed sequence tags, J. Struct. Funct. Genomics 14 (2013) 11-18.

112.S. Subramanian, Y. Fu, R. Sunkar, W.B. Barbazuk, J.K. Zhu, O. Yu, Novel and nodulation-regulated microRNAs in soybean roots, BMC Genomics 9 (2008) 160.

113.J. Zhang, L. Wei, J. Jiang, A.S. Mason, H. Li, C. Cui, L. Chai, B. Zheng, Y. Zhu, Q. Xia, L. Jiang, Genome-wide identification, putative functionality and interactions between lncRNAs and miRNAs in Brassica species, Sci. Rep. 8 (2018) 1-11.

114.B. Avşar, D. Esmaeilialiabadi, Identification of in silicomirnas in four plant species from fabaceae family, Agrofor. 3 (2018) 122-130.

115.H.J. Kim, K.H. Baek, B.W. Lee, D. Choi, C.G. Hur, In silico identification and characterization of microRNAs and their putative target genes in Solanaceae plants, Genome 54 (2011) 91-98.

116.B. Zhang, X. Pan, C.H. Cannon, G.P. Cobb, T.A Anderson, Conservation and divergence of plant microRNA genes, Plant J. 46 (2006) 243-59.

117.R.S. Taylor, J.E. Tarver, S.J. Hiscock, P.C.Donoghue, Evolutionary history of plant microRNAs, Trends Plant Sci. 19 (2014) 175-182.

118.M.J. Axtell, J.L. Bowman, Evolution of plant microRNAs and their targets, Trends Plant Sci. 13 (2008) 343-349.

119.L. Li, J.K. Popko, X.H. Zhang, K. Osakabe, C.J Tsai, C.P. Joshi, V. L. Chiang, A novel multifunctional O-methyltransferase implicated in a dual methylation pathway associated with lignin biosynthesis in loblolly pine, Proc. Natl. Acad. Sci. 94 (1997) 5461-6. 
120.Z. Ma, C. Coruh, M.J. Axtell. Arabidopsis lyrata small RNAs: transient MIRNA and small interfering RNA loci within the Arabidopsis genus, Plant Cell Rep. 22 ( 2010) 1090103.

121.M.A. German, S. Luo, G. Schroth, B.C Meyers, P.J. Green, Construction of Parallel Analysis of RNA Ends (PARE) libraries for the study of cleaved miRNA targets and the RNA development, Nat. Protoc. 4 (2009) 356.

122.H. Vaucheret, F. Vazquez, P. Crété, D.P. Bartel, The action of ARGONAUTE1 in the miRNA pathway and its regulation by the miRNA pathway are crucial for plant development, Genes Dev. 18 (2004) 1187-97. 


\begin{tabular}{|c|l|c|}
\hline No & \multicolumn{1}{|c|}{ Steps } & No of ESTs \\
\hline 01 & Retrieval of previously known mature miRNA sequences from miRBase & 6386 \\
\hline 02 & Retrieval of EST sequences from jute genome & 826 \\
\hline 03 & Non-redundant miRNA sequences & 3350 \\
\hline 04 & Non-redundant ESTs of jute genome & 763 \\
\hline 05 & Search for potential miRNAs in jute genome by BLASTn & 621 \\
\hline 06 & Candidate ESTs with non-protein coding sequences after Blastx & 36 \\
\hline 07 & Putative pre-miRNA sequences with Hair-loop secondary structure & 05 \\
\hline 08 & Identification of newly identified miRNA family & 05 \\
\hline 09 & Prediction and functional of putative miRNA targets & \multicolumn{1}{|c|}{} \\
\hline
\end{tabular}

\section{Tables}

Table 1: Steps involved in the characterization of putative miRNA from ESTs of jute genome 


\begin{tabular}{|c|c|c|c|c|c|c|c|}
\hline 09 & \multicolumn{2}{|c|}{ Final candidate of conserved newly identified miRNA in the jute genome } & \multicolumn{2}{c|}{05} \\
\hline \hline Predicted miRNAs of & $\begin{array}{c}\text { Accession } \\
\text { Jute }\end{array}$ & $\begin{array}{c}\text { miRNAs of } \\
\text { miRBase }\end{array}$ & Length & Mismatch & $\begin{array}{c}\text { A+U } \\
\text { conten } \\
\mathrm{t}(\%)\end{array}$ & MFE & MFEI \\
\hline
\end{tabular}

Table 2: Putative miRNA in the jute genome with suggested criteria 


\begin{tabular}{|c|c|c|c|c|c|c|c|}
\hline ACACAACUGUUUCUGCUU & GR463689 & $\begin{array}{c}\text { gma- } \\
\text { miR1536 }\end{array}$ & 18 & 3 & 61 & $\begin{array}{c}- \\
23.30\end{array}$ & -0.58 \\
\hline UAAGCAACCCAGAGAGUU & HS411997 & $\begin{array}{c}\text { bra- } \\
\text { miR9567- } \\
3 p\end{array}$ & 18 & 3 & 65 & $\begin{array}{c}- \\
17.60\end{array}$ & -0.60 \\
\hline GACAAAGAUCUAAGUAGA & FK826577 & $\begin{array}{c}\text { gma- } \\
\text { miR4391 }\end{array}$ & 18 & 3 & 64 & $\begin{array}{c}- \\
14.90\end{array}$ & -0.49 \\
\hline AGGAAGAGAAGAAAGAUG & FK826577 & $\begin{array}{c}\text { fve- } \\
\text { miR11300 }\end{array}$ & 18 & 3 & 64 & $\begin{array}{c}- \\
22.00\end{array}$ & -0.73 \\
\hline AGUUGCUGAUGGGAUGGG & GH985240 & $\begin{array}{c}\text { gra- } \\
\text { miR8689 }\end{array}$ & 18 & 3 & 55 & $\begin{array}{c}- \\
59.60\end{array}$ & -1.56 \\
\hline
\end{tabular}


bioRxiv preprint doi: https://doi.org/10.1101/2020.04.22.056176; this version posted April 27, 2020. The copyright holder for this preprint (which was not certified by peer review) is the author/funder. All rights reserved. No reuse allowed without permission.

Table 3: Putative miRNA targets in the crucial cellular process of Corchorus capsularis 


\begin{tabular}{|c|c|c|c|c|c|}
\hline Target protein & $\begin{array}{c}\text { Putative } \\
\text { Jute miRNA }\end{array}$ & $\begin{array}{c}\text { Target Acc. } \\
\text { No }\end{array}$ & $\begin{array}{c}\text { Inhibition } \\
\text { Type }\end{array}$ & & ological Functions \\
\hline $\begin{array}{c}\text { NAC Domain } \\
\text { Containing Protein }\end{array}$ & $\begin{array}{c}\text { cca- } \\
\text { miR4391 } \\
\text { cca- } \\
\text { miR11300 }\end{array}$ & $\begin{array}{l}\text { AT2G24430 } \\
\text { AT5G64060 }\end{array}$ & Cleavage & & $\begin{array}{l}\text { Lignin biosynthesis } \\
\text { process }[55,56] \\
\text { Secondary cell wall } \\
\text { formation }[55,56]\end{array}$ \\
\hline $\begin{array}{l}S \text {-adenosyl-L-Met- } \\
\text { dependent methyl } \\
\text { transferase }\end{array}$ & $\begin{array}{c}\text { cca- } \\
\text { miR1536, } \\
\text { cca- } \\
\text { miR4391, } \\
\text { cca- } \\
\text { miR8689 }\end{array}$ & $\begin{array}{l}\text { AT3G44870 } \\
\text { AT1G04430 } \\
\text { AT4G01850 } \\
\text { AT1G69523 } \\
\text { AT1G69526 }\end{array}$ & Cleavage & & $\begin{array}{l}\text { Lignin biosynthesis } \\
\text { pathways [57,58] } \\
\text { Formation of plant } \\
\text { secondary cell wall, } \\
\text { pigments, isoflavonoid, } \\
\text { phytoestrogens and } \\
\text { chalcone nodulation } \\
\text { factors [59] }\end{array}$ \\
\hline $\begin{array}{l}\text { WRKY DNA } \\
\text { binding protein } \\
\text { 4, } 8 \& 23\end{array}$ & $\begin{array}{l}\text { cca- } \\
\text { miR9567, } \\
\text { cca- } \\
\text { miR8689 }\end{array}$ & $\begin{array}{l}\text { AT1G13960 } \\
\text { AT5G46350 } \\
\text { AT2G47260 }\end{array}$ & Cleavage & b) & $\begin{array}{l}\text { Regulation of } \\
\text { phenylpropanoid } \\
\text { pathway involved in } \\
\text { lignin biosynthesis } \\
\text { [60,61] } \\
\text { Biosynthesis of } \\
\text { important } \\
\text { pharmaceutical, } \\
\text { aromatherapy and } \\
\text { biofuel [62,63] } \\
\text { Production of } \\
\text { phytohormones and } \\
\text { phytoalexins [64] } \\
\text { Determination of Seed } \\
\text { size and colour [65] }\end{array}$ \\
\hline $\begin{array}{c}\text { 3-dehydroquinate } \\
\text { synthase }\end{array}$ & $\begin{array}{c}\text { cca- } \\
\text { miR1536 }\end{array}$ & AT3G28760 & Cleavage & a) & $\begin{array}{l}\text { Lignin biosynthesis } \\
\text { pathways [66] }\end{array}$ \\
\hline
\end{tabular}




\begin{tabular}{|c|c|c|c|c|c|}
\hline & & & & b) & $\begin{array}{l}\text { Shikimate and } \\
\text { aromatic amino acid } \\
\text { biosynthetic pathways } \\
{[66]}\end{array}$ \\
\hline $\begin{array}{l}\text { Vascular-related } \\
\text { NAC- } \\
\text { Domain (VND)-4 }\end{array}$ & $\begin{array}{c}\text { cca- } \\
\text { miR9567-3p }\end{array}$ & AT1G12260 & Cleavage & b) & $\begin{array}{l}\text { Upregulation of the } \\
\text { genes required for } \\
\text { secondary cell wall } \\
\text { deposition }[67,68] \\
\text { Regulation of cell } \\
\text { death and prevention of } \\
\text { secondary wall defects } \\
\text { in the fibers }[67,68]\end{array}$ \\
\hline $\begin{array}{l}\text { Leucine-rich repeat } \\
\text { (LRR) family } \\
\text { protein (13) }\end{array}$ & $\begin{array}{c}\text { cca- } \\
\text { miR1536, } \\
\text { cca- } \\
\text { miR9567-3p, } \\
\text { cca- } \\
\text { miR4391, } \\
\text { cca- } \\
\text { miR4391, } \\
\text { cca- } \\
\text { miR8689 }\end{array}$ & $\begin{array}{l}\text { AT1G72460 } \\
\text { AT4G29240 } \\
\text { AT5G22320 } \\
\text { AT1G49750 } \\
\text { AT1G53350 }\end{array}$ & Cleavage & a) & $\begin{array}{l}\text { Ligand recognition and } \\
\text { involved in the protein- } \\
\text { protein interaction } \\
\text { process }[69,70]\end{array}$ \\
\hline $\begin{array}{c}\text { Transposable } \\
\text { element gene (87) }\end{array}$ & $\begin{array}{c}\text { cca- } \\
\text { miR1536, } \\
\text { cca- } \\
\text { miR9567-3p, } \\
\text { cca- } \\
\text { miR4391, } \\
\text { cca- } \\
\text { miR4391, } \\
\text { cca- }\end{array}$ & $\begin{array}{l}\text { AT4G04550 } \\
\text { AT1G44045 } \\
\text { AT1G35465 } \\
\text { AT3G48235 } \\
\text { AT3G44705 }\end{array}$ & Cleavage & a) & $\begin{array}{l}\text { Cell cycle regulation, } \\
\text { modulating vesicle } \\
\text { transport, regulating } \\
\text { cellular metabolism } \\
\text { and maintenance of } \\
\text { energy homeostatis } \\
\text { process }[71,72]\end{array}$ \\
\hline
\end{tabular}




\begin{tabular}{|c|c|c|c|c|c|}
\hline & miR8689 & & & & \\
\hline $\begin{array}{c}\text { Protein kinase } \\
\text { superfamily protein } \\
\text { (17) }\end{array}$ & $\begin{array}{c}\text { cca- } \\
\text { miR1536, } \\
\text { cca- } \\
\text { miR9567-3p, } \\
\text { cca- } \\
\text { miR4391, } \\
\text { cca- } \\
\text { miR4391, } \\
\text { cca- } \\
\text { miR8689 }\end{array}$ & $\begin{array}{l}\text { AT2G42960 } \\
\text { AT1G18390 } \\
\text { AT5G56890 } \\
\text { AT4G24480 } \\
\text { AT4G00955 }\end{array}$ & Cleavage & b) & $\begin{array}{l}\text { Components of } \\
\text { different signalling } \\
\text { networks [73] } \\
\text { Cell cycle regulation } \\
\text { [74] } \\
\text { Developmental } \\
\text { processes, modulating } \\
\text { vesicle transport and in } \\
\text { regulating cellular } \\
\text { metabolism [75] }\end{array}$ \\
\hline $\begin{array}{l}\text { Pentatricopeptide } \\
\text { repeat (PPR) } \\
\text { superfamily protein } \\
\text { (9) }\end{array}$ & $\begin{array}{c}\text { cca- } \\
\text { miR1536, } \\
\text { cca- } \\
\text { miR9567-3p, } \\
\text { cca- } \\
\text { miR4391, } \\
\text { cca- } \\
\text { miR4391, } \\
\text { cca- } \\
\text { miR8689 }\end{array}$ & $\begin{array}{l}\text { AT3G54980 } \\
\text { AT5G61400 } \\
\text { AT3G08820 } \\
\text { AT4G14850 } \\
\text { AT1G11710 }\end{array}$ & Cleavage & a) & $\begin{array}{l}\text { Organelle biogenesis, } \\
\text { photosynthesis, } \\
\text { respiration, plant } \\
\text { development and } \\
\text { environmental } \\
\text { responses [76] }\end{array}$ \\
\hline
\end{tabular}

\section{All Legends}

Figure 1: The schematic outline of the total methodology 
Figure 2: Secondary structures of final putative miRNA by using the Zuker folding algorithm of MFOLD software

Figure 3: Alignments of the putative miRNAs of jute genome and its homologues from respective microRNA family

Figure 4: Overall nucleotide compositions (\%) of putative miRNA from Corchorus capsularis compared with the homologues mRNA of miRBase.

Supplementary Table 1: Non-coding EST sequence containing the predicted precursor miRNA

Supplementary Table 2: Around 1052 targets of five miRNAs by the psRNATarget

Supplementary File 1: A total of 6386 of plant miRNA from miRBase database.

Supplementary File 2: Retrieved 826 EST sequences of Corchorus capsularis

Supplementary File 3: Total of 3350 miRNA after redundancy screening

Supplementary File 4: Total of 763 non-redundant EST sequences of jute

Supplementary File 5: Potential 621 ESTs of jute genome towards the prediction putative miRNA

Supplementary File 6: Total of 36 Putative non-coding EST sequences of jute genome

Supplementary File 7: Non-coding ESTs of jute genome failed to fulfil the suggested criteria 
Retrieval of ESTs from Corchorus capsularis

\section{Genome, EST \& miRNAs}

Acquisition of reference miRNA form miRBAse

Search for potential putative miRNAs in $C$. parvum genome

Screening for the non-coding miRNA candidates

Identification of novel miRNA with reported parameters

Prediction of pre-miRNA with secondary structure

Nomenclature and annotation of predicted miRNAs family

Prediction and functional annotation of putative miRNA targets

Literature review and pathway analysis of putative miRNA target
* C. capsularis Genome Assembly (GCA_001974805.1)

* Non-redundant ESTs : 763

* Non-redundant miRNAs: 3350

\section{Resource Used}

* NCBI

* GeneBank

* mirBase

* BLASTn

BLASTx

* miREval

* Mfold

* ClustalOmega

* Jalview

* psRNATarget

Literature study 

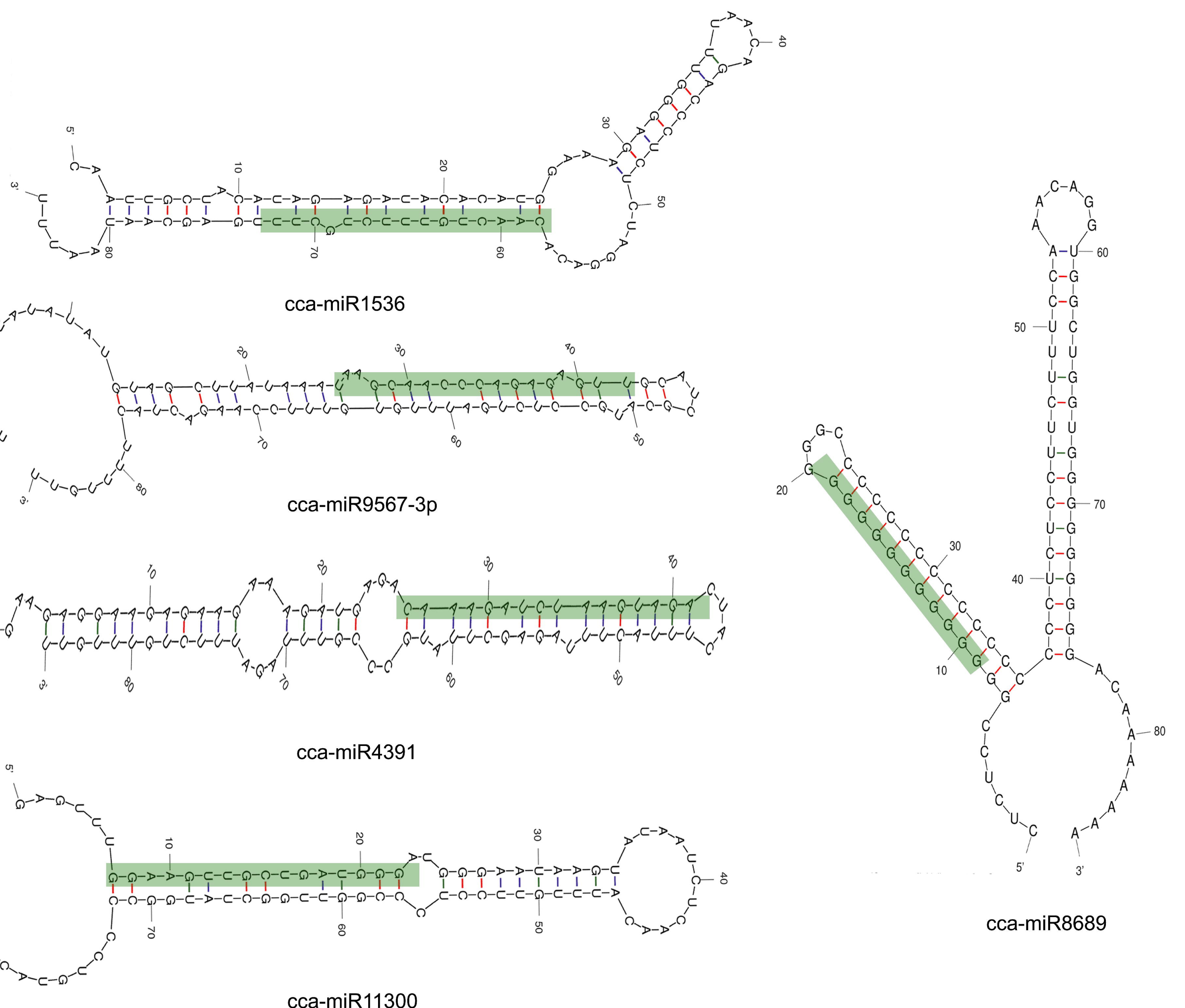
cca-miR 1536

gma-miR1536

CCA-miR9567-3P

bra-mi $9567-3$ P

cca-miR4391

gma-miR4391

CCa-MIR 11300

fve-MIR 11300

cca-miR8689

gra-miR8689
1 ACACAACUGUUUCUGCUU 18

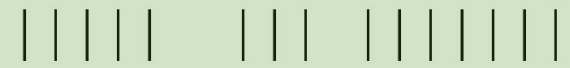

18 ACACAUUUGUCUCUGCUU 1

1 UAAGCAACCCAGAGAGUU 18

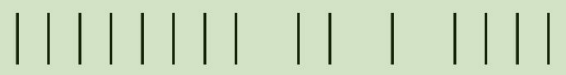

19 UAAGCAACACAUAUAGUU 2

1 GACAAAGAUCUAAGUAGA 18

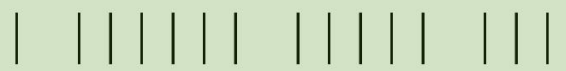

5 GGCAAAGAACUAAGAAGA 22

1 AGGAAGAGAAGAAAGAUG 18

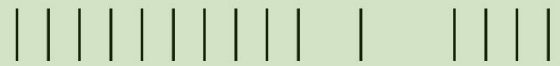

21 AGGAAGAGAACAGUGAUG 4

1 AGUUGCUGAUGGGAUGGG 18<smiles>[14CH4]</smiles>

3 AgGUGCUCAUGGGCUGGG 20 


\section{$\square$ Adenine $\square$ Uracil $\square$ Guanine $\square$ Cytosine}

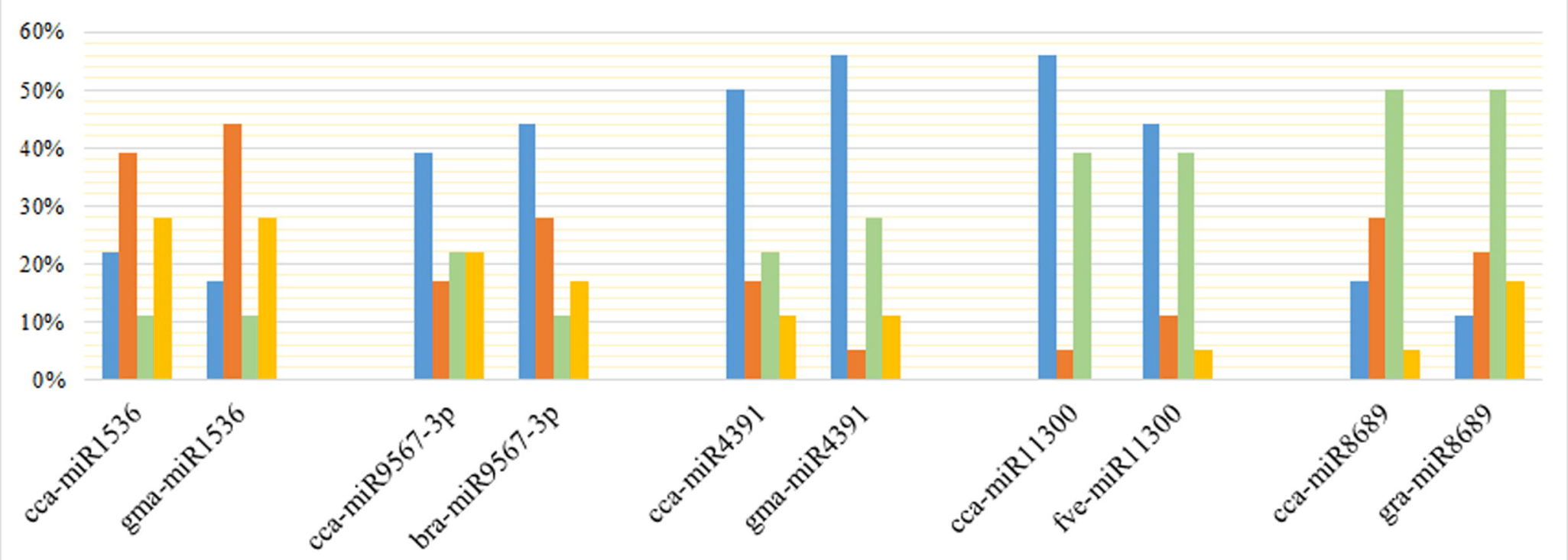

